\title{
Hubungan self-esteem dengan penyesuaian diri terhadap masa pensiun pada pensiunan Perwira Menengah TNI AD
}

\author{
Dinie Ratri Desiningrum* \\ Universitas Diponegoro
}

\begin{abstract}
ABSTRAK
Masa pensiun akan dialami oleh setiap orang yang bekerja, termasuk para pensiunan Perwira Menengah Tentara Nasional Indonesia Angkatan Darat (Pamen TNI AD). Di masa pensiun para pensiunan harus melakukan penyesuaian diri terhadap perubahan-perubahan yang dialaminya, yang mencakup perubahan kondisi fisik, sosial, dan finansial. Penyesuaian diri seseorang dapat dipengaruhi oleh kondisi psikologisnya. Penelitian ini bertujuan untuk melihat penyesuaian diri para pensiunan Pamen TNI AD di dalam menjalani masa pensiun, ditinjau dari self-esteem-nya. Metode yang digunakan adalah korelasional, dan penjaringan data dilakukan melalui self-administered questionnaire. Hasil penelitian menunjukkan adanya hubungan yang signifikan antara self-esteem para pensiunan Pamen TNI AD dengan kemampuan penyesuaian diri terhadap masa pensiunnya. Secara spesifik, ketiga aspek penyesuain diri (fungsi sosial, morale, dan kesehatan fisik) dapat diprediksikan oleh selfesteem.
\end{abstract}

Kata kunci: Self-esteem, penyesuaian diri, pensiun

\section{The relationships of self-esteem with self-adjustment towards pension among Middle Officers Of TNI AD}

\begin{abstract}
Retirement will be experienced by everyone who works, including those who works in the National Army of Indonesia (TNI AD). In retirement the retirees would have to adjust themselves to every changes, including physical, social, and financial changes. Adjustment of a person can be affected by psychological conditions. The present study examines retirement among TNI AD retiree, in terms of their self-esteem. The approach was correlational through a self-administered questionnaire. The results yielded a significant effect of self-esteem on TNI AD retirees adjustment capability. Specifically, social fuctioning, morale, and physical health were all predicted by self-esteem.
\end{abstract}

Keywords: Self-esteem, self-adjustment, retirement

* Korespondensi mengenai penelitian ini dapat dilayangkan kepada Dinie Ratri Desiningrum melalui e-mail: dn.psiundip@gmail.com 
Tentara Nasional Indonesia (TNI) merupakan suatu bidang pekerjaan yang mengemban tugas-tugas kenegaraan terutama yang berkaitan dengan masalah pertahanan dan keamanan negara. Di dalam TNI terdapat jenjang hierarkis yang jelas dan tegas, yang ditandai simbolsimbol kepangkatan. Dalam sistem kerjanya, keseluruhan kegiatan yang menyangkut tugas pekerjaan harus melewati jenjang hierarki yang ada (Andi, 2003).

Setiap jenjang kepangkatan mempunyai porsi tugas, tanggung jawab, dan kewenangan yang disesuaikan dengan jenjang tersebut. Adapun jenjang kepangkatan ini meliputi: Tamtama, Bintara, Perwira Pertama, Perwira Menengah dan Perwira Tinggi (Pusat Penerangan ABRI, 1997). Dalam penelitian ini, saya mengkhususkan penelitian ini pada jenjang kepangkatan Perwira Menengah. Pada jenjang kepangkatan ini mereka telah menjalani masa kerja yang panjang sebagai perwira, dan kondisi ini telah memberi suatu kesempatan kepada mereka untuk lebih menghayati peranan, wewenang, dan tanggung jawabnya sebagai seorang perwira menengah (Sri, 2006). Dengan pangkat, jabatan, dan wewenang yang dimilikinya mereka selalu dihormati, dipatuhi, diberi banyak fasilitas yang memberi banyak kemudahan selama kariernya. Mereka sangat dihormati masyarakat umum terlebih dengan pangkat yang tergolong tinggi, selain itu merekapun mendapatkan penghormatan dari negara ketika mereka mencapai suatu prestasi yang dinilai sukses, bisa berupa kenaikan pangkat, jabatan, atau pemberian tanda jasa. Semakin tinggi pangkat dan jabatannya, maka semakin besar pula wewenang dan kuasa yang dimilikinya. Semua itu, seperti yang diungkapkan Burns (2000) dapat menumbuhkan suatu penghargaan diri yang tinggi selama mereka masih bekerja.

Manusia tidak dapat bekerja terus menerus sepanjang hidupnya, akan tiba suatu masa pensiun, yakni berakhirnya masa kerja formal seseorang dan dimulainya suatu peran baru dalam hidup, harapan-harapan baru, serta pendefinisian kembali tentang diri (Turner \& Helms, 2001). Masa pensiun ini tidak selamanya mudah dilalui oleh para pensiunan dan dapat dinilai berbeda oleh setiap pensiunan (Aiken, 1995). Seperti beberapa keterangan yang diperoleh dari hasil wawancara terhadap 12 orang pensiunan perwira menengah, yang menjadi anggota Persatuan Purnawirawan Angkatan Bersenjata Republik Indonesia (Pepabri) tingkat ranting, Cimahi Tengah, bulan Juni -Juli 2010, mereka menilai masa pensiun yang dijalaninya sebagai situasi yang menekan, karena berbagai perubahan setelah pensiun memerlukan banyak penyesuaian diri. Beberapa partisipan menyebutkan bahwa masa pensiun merupakan masa istirahat, sehingga tidak menimbulkan penderitaan atau depresi yang berlarut-larut, dan beberapa partisipan lainnya menilai di masa pensiun mereka dapat meningkatkan kesejahteraan hidupnya melalui aktivitas baru, seperti mengembangkan hobi, mengurus cucu, dan bergabung dalam organisasi sosial.

Individu akan memaknai hidup secara berbeda pada masa pensiunnya, dan melakukan penyesuaian diri terhadap berbagai perubahan (Hurlock, 2004). Penyesuaian diri merupakan usaha individu untuk mengatasi keadaan yang tidak menyenangkan, antara lain konflik, ketegangan, frustrasi, atau stres pada individu. (Lazarus, 1984). Adapun aspek-aspek dari penyesuaian diri, adalah fungsi sosial, moral, dan kesehatan fisik (Lazarus \& Folkman dalam Santrock, 2004). Tidak semua orang dapat menyesuaikan diri dengan perubahan-perubahan tersebut, sehingga menimbulkan ketegangan atau stres pada diri. Stres merupakan hubungan antara individu dengan lingkungan yang oleh individu dinilai membebani atau melebihi kekuatannya dan mengancam kesehatan fisik (Lazarus \& Launier, 1978). Individu melakukan penyesuaian diri dalam aspek fungsi sosial, dengan cara memahami berbagai aturan dalam lungkungan sosialnya, dan hal ini mempengaruhi perilaku individu dalam melakukan interaksi sosial (Calhoun, 2001).

Kedua hal tersebut merupakan proses pertumbuhan kemampuan individu dalam rangka penyesuaian sosial untuk menahan dan mengendalikan diri. Pertumbuhan kemampuan ketika mengalami proses penyesuaian sosial, berfungsi seperti pengawas yang mengatur kehidupan 
sosial dan kejiwaan. Seperti yang dikatakan Freud sebagai hati nurani (super ego), yang berusaha mengendalikan kehidupan individu dari segi penerimaan dan kerelaannya terhadap beberapa pola perilaku yang disukai dan diterima oleh masyarakat, serta menolak dan menjauhi hal-hal yang tidak diterima oleh masyarakat, yang tergolong dalam aspek moral dalam penyesuaian diri individu (dalam Lazarus, 1984).

Penyesuaian diri pensiunan TNI AD berkaitan erat dengan ketiga aspek seperti yang dijelaskan sebelumnya. Dari segi kesehatan fisik, mereka menyadari di penurunan daya tahan tubuh yang menimbulkan beberapa penyakit dan mengubah penampilan fisik mereka. Mereka juga menilai dirinya mengalami penurunan kompetensi (Turner \& Helms, 2001). Dari segi fungsi sosial, mereka cenderung tidak banyak bergaul, karena adanya berbagai perubahan kondisi psikologis berkaitan dengan hilangnya status dan jabatan setelah pensiun, di antaranya timbul penilaian terhadap diri bahwa mereka merasa tidak lagi mendapatkan penghormatan dari lingkungannya, seperti kurang diturutinya keinginan yang mereka kemukakan, sehingga dapat dikatakan mereka tidak lagi memiliki daya untuk mempengaruhi orang-orang di sekitarnya. Ada suatu perasaan bosan dan sepi, serta timbul penilaian bahwa lingkungan tidak lagi memberikan perhatian terhadap dirinya seperti sebelum pensiun. Tidak adanya daya yang dirasakan membuat mereka menilai dirinya kurang berarti dan ada suatu perasaan kekhawatiran akan masa depan yang berlebihan, sehingga dalam hal aspek moral, mengganggu penyesuaian dirinya terhadap aturan-aturan di masyarakat (Papalia \& Olds, 2004).

Penyesuaian diri seseorang dapat dipengaruhi oleh kondisi psikologisnya, termasuk kepribadiannya (Lazarus \& Folkman dalam Martin et al., 1997). Para pensiunan dapat memiliki penilaian tersendiri terhadap diri setelah mengalami perubahan kondisi di masa pensiunnya ini, yang menyangkut keadaan self-esteem-nya. Keseluruhan keluhan dari hasil wawancara merupakan wujud dari suatu penilaian terhadap diri, yaitu bentuk penghargaan diri (self-esteem) mereka. Self-esteem sebagai salah satu dimensi kepribadian menunjukkan penilaian individu terhadap dirinya, yang nantinya akan menghasilkan bagaimana penerimaan dan penghargaan diri (Coopersmith, 1967). Dengan demikian, rumusan permasalahan yang diangkat dalam penelitian ini adalah, "Bagaimana penyesuaian diri para pensiunan perwira menengah TNI AD di dalam menjalani masa pensiunnya, ditinjau dari self-esteem yang dimiliki?"

\section{METODE}

Penelitian ini dilakukan dengan metode rancangan korelasional dengan melihat hubungan variabel terikat dengan aspek-aspek dari variabel tergantungnya (Cohen et al., 2002). Adapun variabel-variabel yang diteliti adalah self-esteem dan penyesuaian diri.

\section{Partisipan}

Partisipan adalah 48 orang pensiunan Perwira Menengah dengan karakteristik sebagai berikut: (1) Para pensiunan perwira menengah TNI AD yang menjadi anggota Pepabri tingkat Ranting, Kelurahan Baros, Cimahi Tengah, Indonesia; (2) menjalani lama pensiun tidak lebih dari lima tahun; (3) Laki-laki dan telah berkeluarga; (4) tidak cacat fisik maupun mental; dan (5) tidak bekerja setelah pensiun.

\section{Variabel penelitian dan alat ukur}

\section{Self-esteem}

Self-esteem merupakan dimensi kepribadian yang menunjukkan penilaian individu terhadap dirinya dan mencerminkan sejauh mana individu menghargai dirinya. Penilaian ini mencakup area kekuatan (power), keberartian (significance), kebaikan (virtue), dan kemampuan (competence), yang berasal dari penerimaan standar nilai keluarga, rekan dan 
masyarakat umum, serta diri sendiri. Self-esteem diukur dengan menggunakan skala yang saya adaptasi dan kembangkan dari alat ukur Adult version of Coopersmith Self-Esteem Inventory (Ryden, 1978, dalam Maslihah, 1996). Skala ini berlandaskan pada aspek-aspek self-esteem usia lanjut (Coopersmith, 1967) yang disesuaikan dengan kepensiunan (Turner \& Helms, 2001). Alat ukur ini sangat reliabel $(\alpha=.92)$, dengan contoh aitem sebagai berikut: (1) "Saya merasa keluarga menerima saya apa adanya setelah pensiun", (2) "Akibat kepensiunan ini, saya merasa nasihat saya tidak lagi dihiraukan oleh orang-orang di sekitar saya" (skor terbalik/reverse scored).

\section{Penyesuaian Diri}

Penyesuaian diri merupakan usaha individu untuk mengatasi keadaan yang tidak menyenangkan, antara lain konflik, ketegangan, frustrasi, atau stres pada individu, yang dalam penelitian ini dikarenakan masa pensiun yang dialaminya. Lazarus dan Folkman (1990) mengungkapkan tiga aspek penyesuaian diri, yaitu fungsi sosial, morale, dan kesehatan fisik. Alat ukur yang digunakan merupakan skala dari Matteson dan Ivancovich (1982) yang juga dikembangkan oleh Lazarus dan Folkman (1990) (dalam Maslihah, 1996), yang kemudian saya adaptasi sesuai dengan perubahan-perubahan di masa pensiun (Turner \& Helms, 2001). Alat ukur ini memiliki reliabilitas yang tinggi $(\alpha=.91)$, dengan contoh aitem sebagai berikut: (1) "Kini banyak waktu luang yang bisa saya manfaatkan untuk menjalankan beberapa tugas rumah tangga", (2) "Saya merasa kesulitan dalam beraktivitas setelah tidak lagi mendapatkan fasilitas kendaraan dinas" (aitem dengan pemberian skor terbalik/reverse scored).

\section{Prosedur Penelitian}

Penelitian ini dilaksanakan pada Bulan Juni-Agustus 2010, di Cimahi, pada Organisasi Pepabri, Tingkat Ranting, Kelurahan Baros, Cimahi Tengah, Indonesia. Pengumpulan data dilakukan dengan mendatangi tempat tinggal responden yang berlokasi di sekitar Kompleks Kebon Rumput, Sriwijaya, dan Sam Ratulangi, Cimahi Tengah. Para partisipan secara sukarela mengisi kuesioner yang telah saya persiapkan. Selain itu, dengan persetujuan partisipan, saya juga melakukan observasi dan wawancara kepada partisipan sebagai upaya mendapatkan data penunjang.

\section{HASIL}

\section{Hubungan self-esteem dengan aspek-aspek penyesuaian diri}

Korelasi antara self-esteem dengan aspek-aspek penyesuaian diri dapat dilihat pada Tabel 1. Dari hasil analisis korelasi diketahui bahwa self-esteem memberikan peranan sekitar $41 \%$ terhadap aspek fungsi sosial dari penyesuaian diri, self-esteem juga memberikan peranan sebesar $78 \%$ terhadap aspek moral, dan $41 \%$ terhadap aspek kesehatan fisik.

Tabel 1. Hubungan self-esteem dengan aspek-aspek penyesuaian diri

Aspek-aspek penyesuaian diri

Fungsi sosial

$.64^{*}$

Morale

$.88^{*}$

Kesehatan fisik

$.64^{*}$

${ }^{*} p<.01$ 


\section{Analisa deskriptif}

Dapat dilihat pada Tabel 2 dan 3, tampak bahwa self-esteem dan penyesuaian diri mayoritas partisipan berada dalam tingkatan sedang, artinya para mayoritas para pensiunan cukup menghargai dirinya dan menilai diri secara positif dan mampu menyesuaikan diri dengan keadaan pensiunnya.

Tabel 2. Self-esteem partisipan

\begin{tabular}{lcc}
\hline Kategori & Skor & Jumlah (\%) \\
\hline Rendah & $30-69$ & 4 \\
Sedang & $70-109$ & 58 \\
Tinggi & $110-150$ & 38 \\
\hline
\end{tabular}

Tabel 3. Penyesuaian diri partisipan

\begin{tabular}{lcc}
\hline Kategori & Skor & Jumlah (\%) \\
\hline Rendah & $43-99$ & 3 \\
Sedang & $100-156$ & 59 \\
Tinggi & $157-172$ & 38 \\
\hline
\end{tabular}

\section{Analisis penunjang}

Tabel 4 dan 5 menggambarkan rekapitulasi data penunjang (melalui observasi dan wawancara). Mayoritas pensiunan merasakan stres pada masa awal menjalani masa pensiunnya, namun para partisipan kemudian mulai menerima keadaan pensiunnya dan melakukan banyak sosialisasi terhadap lingkungan, komunitas, maupun keluarga.

Tabel 4. Kondisi emosional partisipan

\begin{tabular}{lc}
\hline Kondisi emosi saat pensiun & Jumlah\% \\
\hline Stres & 69 \\
Kecewa & 38 \\
Bingung & 31 \\
\hline
\end{tabular}

Tabel 5. Strategi penanggulangan stress partisipan

\begin{tabular}{lc}
\hline Strategi & Jumlah\% \\
\hline Menyendiri & 8 \\
Menerima keadaan pensiun & 31 \\
Menyibukkan diri dalam aktivitas & 15 \\
Mengunjungi keluarga & 23 \\
Bersosialisasi & 38 \\
\hline
\end{tabular}




\section{DISKUSI}

Masa pensiun adalah berakhirnya masa kerja formal seseorang dan dimulainya suatu peran baru dalam hidup, harapan-harapan baru, serta pendefinisian kembali tentang diri (Turner \& Helms, 2001). Bagi perwira TNI, khususnya Pamen TNI AD, selama masa kerjanya, mereka memperoleh berbagai keuntungan baik secara finansial, berupa pendapatan yang cukup tinggi dan segala fasilitas yang diberikan, juga keuntungan psikis berupa penghormatan dan perhatian dari orang-orang di sekitarnya, maka pensiun bagi mereka merupakan suatu momentum yang berarti berakhirnya segala keuntungan tersebut sehingga membutuhkan suatu penyesuaian diri agar dapat mereduksi stres yang timbul. Hasil pengujian hipotesis yang dilakukan melalui analisis statistik menunjukkan bahwa terdapat hubungan yang positif dan signifikan antara self-esteem dengan kemampuan penyesuaian diri terhadap masa pensiun pada pensiunan Pamen TNI AD. Semakin tinggi self esteem para pensiunan maka semakin baik kemampuan penyesuaian dirinya terhadap masa pensiun yang dialaminya. Sebaliknya, semakin rendah self-esteem para pensiunan, maka semakin buruk kemampuan penyesuaian dirinya terhadap masa pensiun. Artinya, untuk mereduksi stres akibat masa pensiun yang dijalaninya, maka dibutuhkan suatu self-esteem yang tinggi agar individu dapat melakukan penyesuaian diri.

Self-esteem akan memproyeksikan cara pandang individu terhadap situasi lingkungannya, dan akan mempengaruhi pula bagaimana para pensiunan Pamen TNI-AD berespon dalam menyesuaikan diri dengan perubahan-perubahan di masa pensiun yang dialaminya. Penelitian ini menunjukkan bahwa self-esteem memiliki kontribusi yang cukup besar terhadap penyesuaian diri pensiunan Pamen TNI AD.

Dengan melihat data penunjang penelitian ini, sebagian besar pensiunan Pamen TNI AD memiliki self-esteem dan penyesuaian diri yang tergolong sedang, artinya mereka menilai harga diri mereka cukup baik dan mereka tergolong cukup mampu menyesuaikan diri dengan masa pensiunnya. Tingkatan sedang ini artinya, Pamen TNI AD yang menjadi partisipan di dalam penelitian ini pada awalnya merasakan stres menjalani masa pensiunnya. Namun kemudian, dengan self-esteem yang dimilikinya, para partisipan berusaha melakukan penyesuaian diri.

Adapun tuntutan yang berasal dari lingkungan seringkali menimbulkan suatu kondisi stres tertentu yang bisa memperburuk keadaan secara fisik dan emosional para pensiunan. Sesuai dengan pendapat Lazarus (dalam Lazarus, \& Launier, 1978) bahwa apabila terjadi kesenjangan, ketidakseimbangan antara tuntutan dan kemampuan maka akan timbul suatu keadaan stres. Upaya penanggulangan stres yang dilakukan subjek merupakan bentuk-bentuk dari penyesuaian diri (strategi penanggulangan stres ini dapat dilihat melalui data penunjang).

Penyesuaian diri menurut Lazarus dan Folkman (dalam Calhoun, 2001) meliputi tiga aspek, yaitu fungsi sosial, moral, dan kesehatan fisik, dan hasil penelitian menunjukkan bahwa self esteem memiliki hubungan yang signifikan dengan ketiganya. Penyesuaian diri dalam fungsi sosial adalah kemampuan individu untuk mengatasi konflik, frustrasi dan kesulitan-kesulitan dalam diri dan berhubungan dengan relasi sosial. Untuk aspek moral ditunjukkan bahwa self esteem juga mempengaruhi bagaimana mereka memandang dan menilai dirinya dan kondisi kehidupannya. Ada dari mereka yang menilai diri sebagai pensiunan yang gagal, juga terdapat penurunan minat dan semangat dalam beraktivitas. Dalam hal kesehatan fisik, diketahui bahwa self esteem mempengaruhi pula kondisi mereka seperti munculnya penyakit-penyakit, penurunan kekuatan fisik dan aktivitas.

\section{Kesimpulan dan saran}

Beberapa hal yang dapat disimpulkan dari penelitian ini, adalah:

1. Terdapat hubungan yang signifikan antara self-esteem para pensiunan Pamen TNI AD dengan kemampuan penyesuaian diri masa pensiunnya. 
2. Terdapat hubungan yang signifikan antara self-esteem dan ketiga aspek penyesuaian diri, yaitu fungsi sosial, morale, dan kesehatan fisik.

Sedangkan saran yang dapat diajukan adalah sebagai berikut:

1. Saran pengembangan penelitian: agar dilakukan penelitian lanjutan untuk lingkup partisipan yang lebih luas lagi; atau dengan kasus dan rentang usia yang berbeda.

2. Saran aplikatif: bagi pasangan dan keluarga dari pensiunan agar memberikan dukungan psikologis yang berarti demi meningkatkan self-esteem subjek.

3. Bagi masyarakat yang tergolong usia dewasa akhir agar memahami permasalahan pensiun, sehingga dapat berempati dan mempersiapkan diri ketika menjalani pensiun.

\section{REFERENSI}

Aiken, Lewis R. (1995). Aging: An introduction to gerontology. California: Sage Publication.

Andi, Mappiare (2003). Journal of Adulthood Psychology. Usaha Nasional, 2, 11

Burns, R. B. (2000). The self concept in theory, measurement, \& development. New York: Longman..

Coopersmith, S. (1967). The antecedent of self-esteem. San Fransisco: Davis, W. H. Freeman \& Company.

Calhoun, Acocella (2001). Psychology about adaptation \& human relationship, $3^{\text {rd }}$ ed. New York : Mc Graw-Hill.

Cohen, R., Montague, P., Nathanson, L., \& Swerdik, M. (2002). Psychological testing : test $\&$ measurement, $5^{\text {th }}$ Ed, California: Mayfield Publishing Company.

Hurlock, E. B. (2004). Psikologi perkembangan: Suatu pendekatan sepanjang rentang kehidupan, Edisi ke-10, Jakarta: Erlangga.

Lazarus, R., \& Folkman, S. (1990). Stress appraisal \& coping, New York: Springer Publishing Company.

Lazarus, R., \& Launier, R. (1978). Stress-related transaction between person \& environment. Dalam: Lewis, M. (Eds) Perspective in interactional psychology, New York: Plenum Press.

Lazarus, R.S. (1984). Pattern of adjustmen. 3rd Ed. Tokyo: Mc Graw Hill.

Martin, G. L., \& Osborne, J. G. (1997). Psychological Adjustment \& Everyday Living. New Jersey: Prentice Hall.

Maslihah S. (1996). Studi mengenai Hubungan antara Self Esteem dan Penyesuaian Diri pada Wanita Infertil, Skripsi sebagai syarat menempuh ujian sarjana di Psikologi UNPAD. unpublished.

Papalia, D. E., \& Olds, S. W. (2004). Human development, $9^{\text {th }}$ Ed. New York: Mc Graw Hill.

Pusat Penerangan ABRI (1997). ABRI, pejuang dan prajurit. Markas Besar Angkatan Bersenjata Republik Indonesia.

Santrock, J. W. (2004). Life span development. $5^{\text {th }}$ Ed. New York: Mc Graw Hill.

Sri, S. (2006). 36 Tahun BABEK ABRI. Staf Pembinaan BABEK ABRI. Jakarta: PT Kharisma Indonesia.

Turner, J. S., \& Helms, D. B. (2001). Lifespan Development, $3^{\text {rd }}$ Ed. United State: Holt, Rinehart \& Winston. 